\title{
QUESTÃO FUNDIÁRIA EM ÁREAS PROTEGIDAS: UMA EXPERIÊNCIA NO PARQUE ESTA- DUAL DA PEDRA BRANCA (PEPB), RIO DE JANEIRO, BRASIL
}

\section{Land tenure in protected areas: a case study in the State Park of Pedra Branca, Rio de Janeiro, Brazil}

Allan Yu Iwama

UNICAMP, Campinas, São Paulo, Brasil. allan.iwama@gmail.com

Fábio Bueno de Lima Instituto de Pesquisas Ecológicas (IPE), Nazaré Paulista, São Paulo, Brasil. buenofb@hotmail.com

Angela Pellin

Instituto de Pesquisas Ecológicas (IPE), Nazaré Paulista, São Paulo, Brasil. angela@arvorar.com

Artigo recebido em 27/03/2013 e aprovado para publicação em 13/01/2014.

RESUMO: A questão fundiária em Unidades de Conservação no Brasil tem sido um dos grandes desafios para sua gestão, sobretudo àquelas situadas no meio urbanizado, como é o caso do Parque Estadual da Pedra Branca (PEPB), localizado no oeste do município do Rio de Janeiro. Para garantir uma adequada gestão da UC, este trabalho apresenta um diagnóstico fundiário para subsidiar o Plano de Manejo do PEPB. Baseado no levantamento de dados secundários e aplicação de questionários estruturados (316 entrevistas, representando $29 \%$ do total estimado de moradias) sobre a questão fundiária em áreas do seu interior/ entorno imediato para identificar elementos chaves para contribuir para a gestão do PEPB. Os resultados indicam seis zonas $(\mathrm{Z})$ que traduzem algumas tipologias de ocupação nos bairros do entorno do PEPB, mostrando uma heterogeneidade de ocupações, com moradores de classe alta, média e baixa, incluindo áreas de favelas; agricultores que moram e sobrevivem das atividades econômicas desenvolvidas no interior dessa UC; e residentes temporários que utilizam o local para "veraneio". Para a minimização dos conflitos fundiários desta UC, quatro elementos devem ser essenciais: (i) levantamento sistemático de informações em cartórios, para que seja criado um cadastro completo dos imóveis do PEPB; (ii) criação de grupos de trabalho multi-interdisciplinares para a solução de problemas fundiários; (iii) implementação de programas de educomunicação ambiental, visando esclarecimentos sobre a preservação do PEPB; (iv) formalização de acordos entre os moradores do Parque e gestores visando minimizar os atuais conflitos. Palavras-chave: Áreas Protegidas, Questão fundiária, Parque Estadual da Pedra Branca.

ABSTRACT: The land tenure has been a challenge for the management of protected areas in Brazil, mainly those located in urban areas, such as the 'Pedra Branca' State Park (PEPB) in the west of Rio de Janeiro city. To ensure an adequate management of UC, this paper presents a land tenure analysis for support the Management Plan of PEPB. Based on the secondary data and application of structured questionnaires (316 interviews, representing $29 \%$ of the total estimated housing) on the land tenure in areas inside/around of PEPB boundaries, seeking for some key elements to support the management of PEPB. This survey identified six zones (Z) with some types

DOI: $10.1590 / 1982-451320140106$ 
of occupation in the study area. The results showed that there are diversified occupations, such as residents with high, medium and low income, including 'favelas', subsistence agricultures and temporary residents. This work pointed out to a complexity related to the land tenure in protected areas and highlights the required elements: (i) systematic data survey for the complete registration of properties in PEPB; (ii) organization of a multi-interdisciplinary working groups to solve land tenure problems, (iii) implementation of environmental education and communication programs, seeking explanation on the PEPB conservation as a factor of improving the quality of life, (iv) agreements between the residents of the Park and policy makers to minimize the conflicts caused by the land tenure in PEPB.

Keywords: Protected Areas, Land Tenure, 'Pedra Branca' State Park.

\section{INTRODUÇÃO}

\section{Areas protegidas e a questão fundiária}

Apesar do avanço com o processo de criação de Unidades de Conservação de Proteção Integral (UCPI) como estratégia para a conservação dos recursos naturais, sobretudo após a criação do Sistema Nacional de Unidades de Conservação, lei federal n. ${ }^{\circ}$ 9.985/2000 (BRASIL, 2000), pouco se avançou com medidas institucionais, estudos e levantamentos técnicos para se tratar a questão fundiária destas áreas protegidas. Segundo Rocha et al. (2010), no período de 1937 a 2008 foram criadas 65 UCPIs nacionais e, até 2000 (quando haviam 44 UCPIs), 66\% dessas UCPIs (somente Parques Nacionais) tinham problemas fundiários registrados, sendo que $34 \%$ desses mesmos 44 parques tinham menos da metade de sua superfície sob domínio público (ROCHA, 2002).

No município do Rio de Janeiro, a questão da terra, bem como outros direitos de propriedade, são temas que existem desde o período da colonização. De acordo com Mota (2009), houve uma transição importante da posse da terra com a Constituição de 1824 (BRASIL, 1824) e especificamente com a Lei de Terras em 1850 (BRASIL, 1850), que instituiu direitos de caráter jurídicos e econômicos para a apropriação das terras públicas. Não obstante, a Lei de Terras não pacificou os conflitos de uma sociedade de Antigo Regime (ver MOTA, 2009).

Costa (2002) aponta que os posseiros legitimavam a divisão de suas terras em grandes propriedades (sob a égide da Lei de Terras) e regularizaram suas glebas, facilitando o avanço das ocupações. Segundo Mota (2009), "a posse institucionalizou-se como um costume e o posseiro como figura emblemática na sociedade brasileira". Neste contexto, atualmente existem diversos agricultores na região oeste do Rio de Janeiro que, apesar de serem a terceira ou quarta geração na propriedade, não possuem documentos oficiais que comprovem a titularidade da terra.

Dentre outras questões, a inexistência de documentos que comprovem a titularidade da terra por seus ocupantes, é um dos fatores que dificultam e atrasam o processo de regularização fundiária de uma UCPI, a qual deve ser de posse e domínio públicos, o que implica na desapropriação das áreas particulares incluídas em seus limites (ver Lei n. ${ }^{\circ}$ 9985/2000 -BRASIL, 2000). A maioria dos Parques (e outras UCPIs) no Brasil, apesar de já terem sido criados e em alguns casos até mesmo já possuírem infraestrutura administrativa, ainda não se encontram com a situação fundiária resolvida (ver trabalhos de FRIDMAN, 1999; 2009), acarretando problemas institucionais, jurídicos, legais e criminais (AZEVEDO, 2002; COSTA, 2002; SOARES, 2004; 2009; MOTA, 2009; SMA, 2009; INEA, 2009).

\section{Parque Estadual da Pedra Branca (PEPB): área protegida, processo de ocupação e questão fundiária}

Este contexto também pode ser verificado no Parque Estadual da Pedra Branca (PEPB), que foi criado pela Lei Estadual no 2.377/1974 (RIO DE JANEIRO, 1974), abrangendo cerca de $16 \%$ do município do Rio de Janeiro, o que lhe garante o título de maior Unidade de Conservação do município (SMA, 2009). Além disso, abriga uma exuberante floresta que na sua grande parte ainda se mantém com espécies nativas da Mata Atlântica em diferentes estágios de sucessão (IEF, 1992). Estas características tornam o PEPB o protetor de uma importante formação florestal situada em área urbana, possuindo uma área de $124,81 \mathrm{~km}^{2}$ (Figura 1). 
Figura 1. Área de estudo - Parque Estadual da Pedra Branca (PEPB), Rio de Janeiro, Brasil

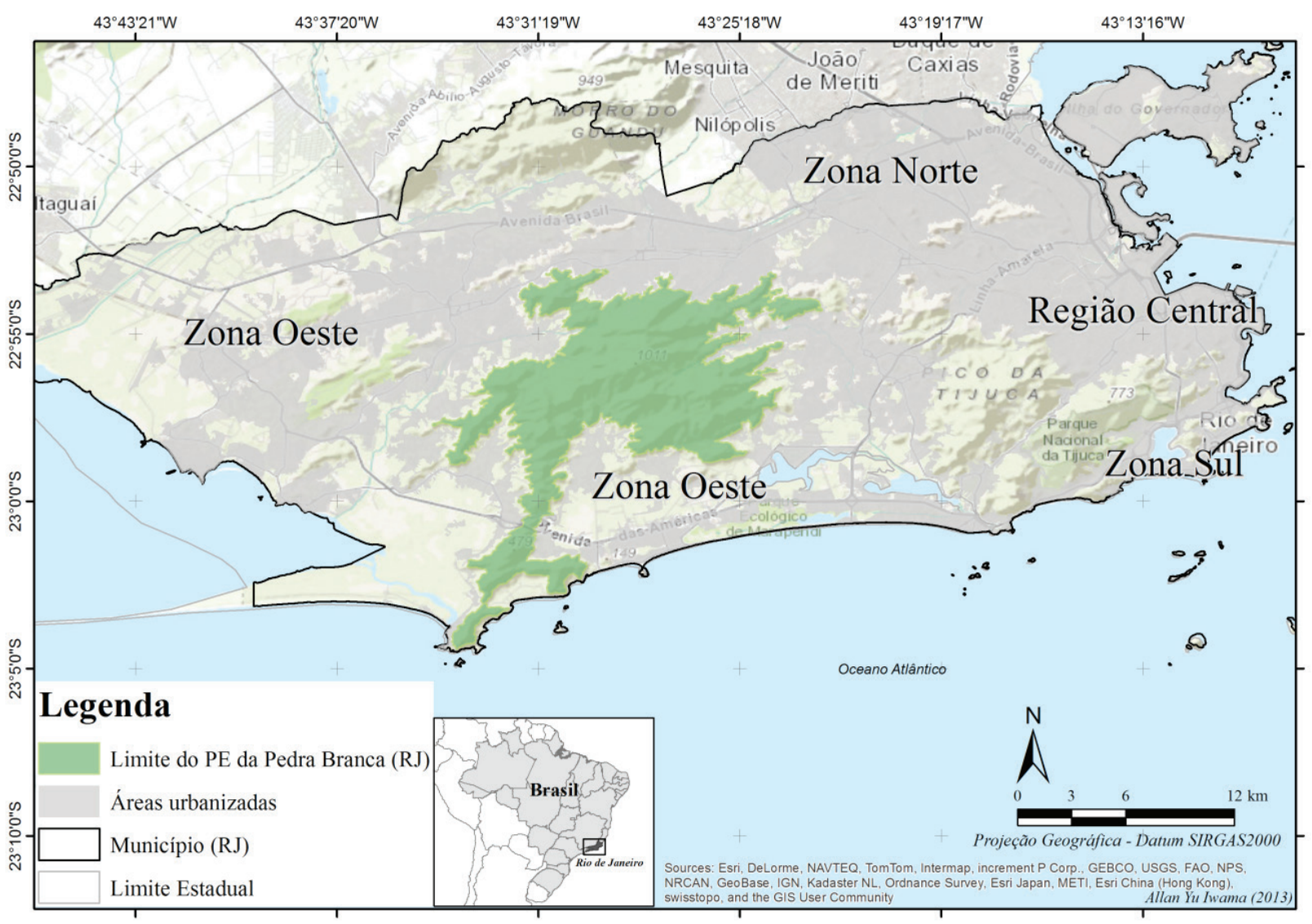

Desde sua criação o PEPB vem passando por uma complexidade de problemas e pressões antrópicas, entre eles, o crescente aumento de população residente no seu interior, e em áreas contíguas aos seus limites. Em termos relativos de área, o PEPB perdeu cerca de $10 \%$ de sua área de floresta no período de 1984 a 1999, redução relativamente maior do que os demais grandes parques do município, sendo que no Parque Nacional da Floresta da Tijuca não houve perdas, e o Parque do Gericinó-Mendanha apresentou uma redução de $3 \%$ para o mesmo período (IPP, 2000).

A realidade fundiária do PEPB ainda não é totalmente conhecida, e atualmente apresenta um mosaico patrimonial, formado por terras de domínio do Estado, de posseiros; de particulares, e ocupações espontâneas (CMA/CNRBMA, 1996; MOTA, 2009). De acordo com Vallejo et al. (2009), a posição geográfica do $\mathrm{PEPB}$, nas proximidades de extensas áreas urbanas em acelerado crescimento, tem nas pressões imobiliárias um dos aspectos mais importantes que conflitam com os propósitos de preservação ambiental. Em determinadas situações, ocorre o isolamento das comunidades residentes na periferia ou no interior desta UC, onde as pessoas são apenas receptoras de informações, não participando efetivamente das ações de proteção e/ou uso dos recursos naturais (MARTINE, 1996; FERNANDEZ, 2009; SATHLER, 2009).

No trabalho de Vallejo et al. (2009), foram levantadas notificações e ocorrências administrativas junto à administração do PEPB no período de 1993 a 2008. Das 458 ocorrências e notificações levantadas, as construções irregulares ( $30 \%$ dos casos) e os casos de incêndio ( $30 \%$ dos casos) são as ocorrências mais frequentes no PEPB. Do total de notificações, 54\% ocorreu em Taquara, seguido por Vargem Grande (14\%), Rio da Prata (10\%), Camorim (6\%), Vargem Pequena (4\%), Curicica (3\%) e Campo Grande (3\%). 


\section{Abordagem de trabalho: justificativa, objetivo $e$ método utilizado}

A falta de informações precisas sobre a questão fundiária no PEPB, juntamente com a heterogeneidade de usos da terra e pressão no interior e nas proximidades do Parque, corroboram e motivam estudos técnicos e científicos sobre a estrutura fundiária da UC, elemento fundamental para garantir sua adequada gestão a curto, médio e longo prazo. Neste contexto, o objetivo deste trabalho foi realizar um diagnóstico fundiário para subsidiar a elaboração do Plano de Manejo do PEPB, feito pelo Instituto de Pesquisas Ecológicas (IPÊ) e administrado pelo Instituto Estadual do Ambiente (INEA), no âmbito do Projeto de Proteção à Mata Atlântica do Estado do Rio de Janeiro (PPMA-RJ). Esse trabalho se baseou em (i) levantamento de dados secundários, consistindo na obtenção de dados dos Censos, 1991, 2000 e 2010 (IBGE, 2011), sendo organizados pelos bairros que fazem limite com o PE da Pedra Branca para identificar o número absoluto de pessoas por bairros e aqueles com maior adensamento populacional; (ii) aplicação de questionários estruturados, com o objetivo de fornecer subsídios para compreender a realidade fundiária atual do Parque, bem como propor alternativas de resolução dos seus conflitos fundiários, visando a proteção dos recursos naturais desta UC. Baseado no modelo de Fichas de Identificação Fundiária - FIF (ver roteiro metodológico de Planos de Manejo - Parques Estaduais, Reservas Biológicas, Estações Ecológicas INEA, 2010), o questionário aplicado buscou abordar pelos menos os seguintes temas/aspectos relacionados ao imóvel/propriedade: (a) tipo de aquisição; (b) tipo de documentação; (c) tempo de ocupação; (iii) abordagem do levantamento fundiário, com a criação de um plano estratégico para elencar os locais potenciais e propriedades a serem aplicados os questionários. Essa estratégia definiu a prioridade das entrevistas em cada local segundo (i) os bairros com maior densidade populacional e limítrofes ao PEPB; (ii) o número estimado de domicílios dentro do PEPB. Ainda sem estimativas precisas da ocupação no interior do $\mathrm{PEPB}$, estudos baseados em fotografias aéreas e levantamento em campo apontam para, aproximadamente, 938 moradias e/ou domicílios, com estimativa de mais de 5 mil habitantes, considerando a cota 100 do Maciço da Pedra Branca e de seus contrafortes, até o ano 2000 (COSTA, 2002). Para realizar a estimativa de domicílios neste trabalho, foi utilizada uma imagem de satélite ortorretificada (mosaico de imagens WorldView de 2010/2011, com 0,5 metros de resolução espacial) e, nas áreas de comunidades/favelas, onde o tamanho e o arranjo espacial das moradias dificultava a identificação individual de cada moradia, foram utilizados os dados do Censo Demográfico 2010. Para estimar o número de domicílios das comunidades situadas totalmente no interior do Parque e conhecidas como "Estrada do Pau da Fome - 764", "Monte da Paz" e "Vale da Benção" em Jacarepaguá, "Rua Pereiro" no Jardim Sulacap, e "Morro do Barata" em Realengo, utilizou-se os dados do setor censitário equivalente às áreas ocupadas por estas comunidades; (iii) as ocupações localizadas no entorno do PEPB e com domínio de milícias ou tráfico foram consideradas de risco para a equipe de levantamento de campo. Por esse motivo, evitou-se o acesso aos bairros de Santíssimo, Padre Miguel, Senador Camará, Senador Vasconcelos. Baseado nesses critérios, no período de julho a agosto de 2011 foram realizadas 316 entrevistas, com saídas em campo orientadas por um pré-levantamento dos locais percorridos com auxílio de imagens WorldView (2011) e do Google Earth.

A abordagem das entrevistas consistiu em uma breve apresentação sobre a importância do PEPB, bem como a data de sua criação e suas finalidades, além do tipo de trabalho que estava sendo executado, no caso, o levantamento fundiário. Em cada entrevista foi utilizado um Global Positioning System (GPS) - Garmim para coletar as coordenadas geográficas e identificar as propriedades que encontravam-se dentro dos limites do PEPB.

\section{RESULTADOS E DISCUSSÃO}

\section{Aspectos populacionais no entorno do PEPB}

Do ponto de vista histórico e de ocupação territorial, a região oeste do município do Rio de Janeiro foi marcada por significativas mudanças das áreas agrícolas já no século 19 (FRIDMAN, 1999; 2009) e no final da década de 30 , nessa região foi 
estabelecida uma zona industrial, estimulando o crescimento populacional. De acordo com Costa (2002), Campo Grande e Jacarepaguá foram as maiores áreas loteadas na zona oeste do município. Na década de 60 , alguns moradores (reconhecidos como posseiros) das áreas dos maciços litorâneos estiveram estabelecidos em terras públicas, nas bordas das denominadas Florestas Protetoras da União (BERNARDES, 1992). De acordo com Bernardes (1992), esses "ocupantes" da terra arrendaram parte do que foi atribuído como seus domínios e os que se mudaram, venderam ou arrendaram a outros os direitos e as benfeitorias. Em determinados lugares, como a região de Vargem Grande, alguns tornaram-se proprietários com subsídios do Banco do Crédito Móvel, embora não seja a maioria. Nas décadas de 1960 e 1970, os bairros da Barra da Tijuca e Recreio dos Bandeirantes, começaram a ser ocupados, estimulados principalmente pela propaganda imobiliária, que incentivou a venda dos empreendimentos realizados na região (FRIDMAN, 1999; 2009; RYFF, 2002). Nas duas últimas décadas, a situação fundiária tem se agravado na medida em que se proliferaram supostos proprietários vendendo terras a terceiros, sem, entretanto, legitimar a situação real delas (COSTA, 2002).

Analisando o crescimento da população nos bairros limítrofes ao PEPB, no período entre 1991, 2000 e 2010, observou-se um crescimento bastante significativo nos bairros de Vargem Pequena, Recreio dos Bandeirantes, Guaratiba e Jacarepaguá. Além disso, Senador Camará, Realengo, Bangu e Campo Grande são os bairros relativamente mais populosos (população maior do que 100 mil habitantes) no período entre 2000 e 2010 (Figura 2 (a)). Estes mesmos bairros, ao lado de Taquara, Senador Vasconcelos e Santíssimo, são os que apresentaram os maiores valores de densidade populacional entre os anos 1991, 2000 e 2010 (Figura 2 (b)). Padre Miguel se destaca como o bairro com maior densidade populacional (alcançando mais do que 13 mil habitantes $/ \mathrm{km}^{2} \mathrm{em} 2000$ e 2010 - Figura 2 (b)). Atualmente, estima-se que o PEPB possui $70 \%$ de seu território em áreas públicas e devolutas contra $30 \%$ de áreas privadas (SATHLER, 2009). Estimativas de arquivos não oficiais (ou sem data precisa de publicação) mostram que apenas cerca de $20 \%$ das terras do PEPB são públicas.

Figura 2. (a) População em 1991, 2000 e 2010 nos bairros contíguos ao PEPB; (b) Densidade populacional (hab/km²) em 1991, 2000 e 2010 nos bairros contíguos ao PEPB (Censo Demográfico - IBGE, 2011).

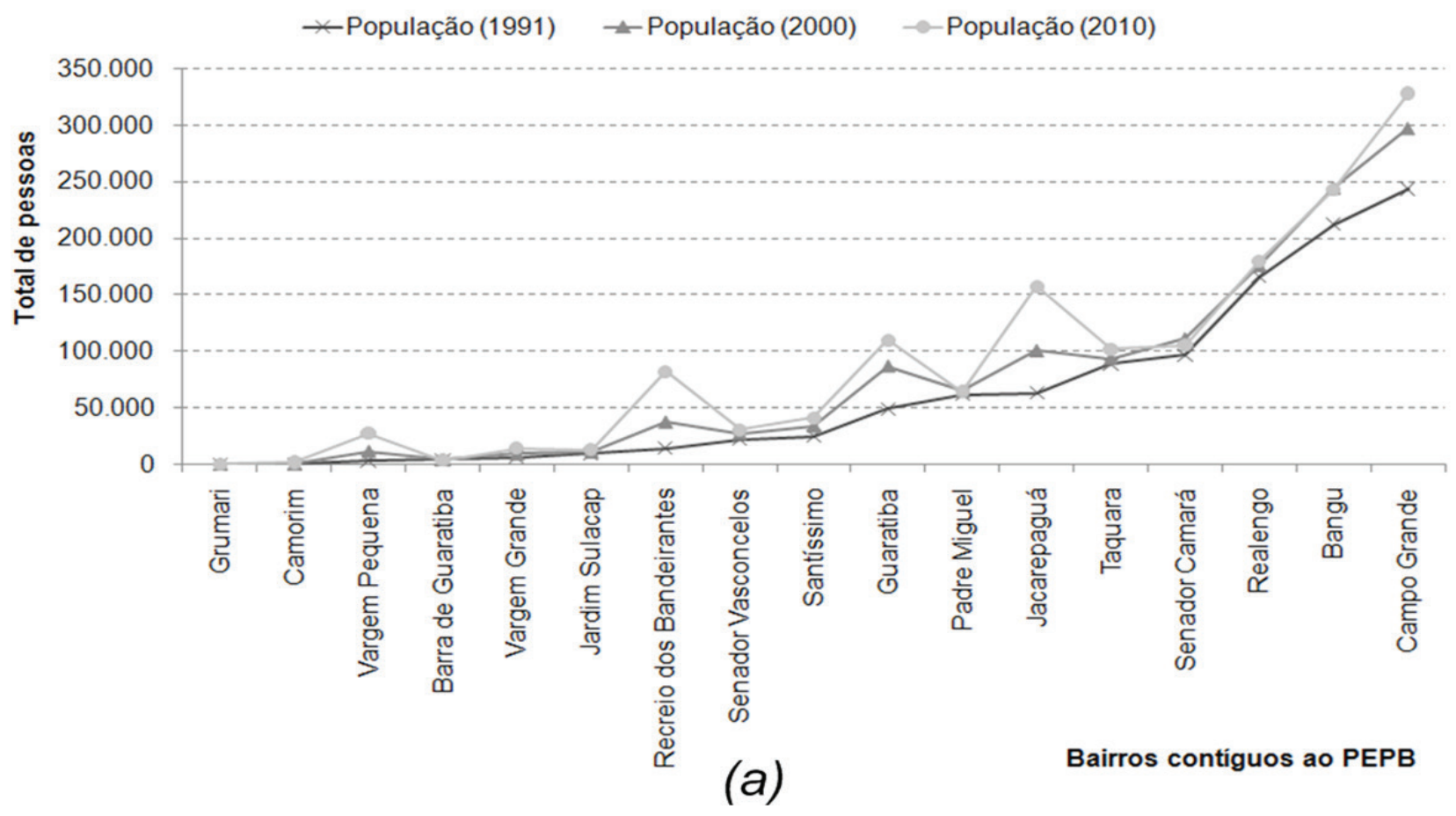




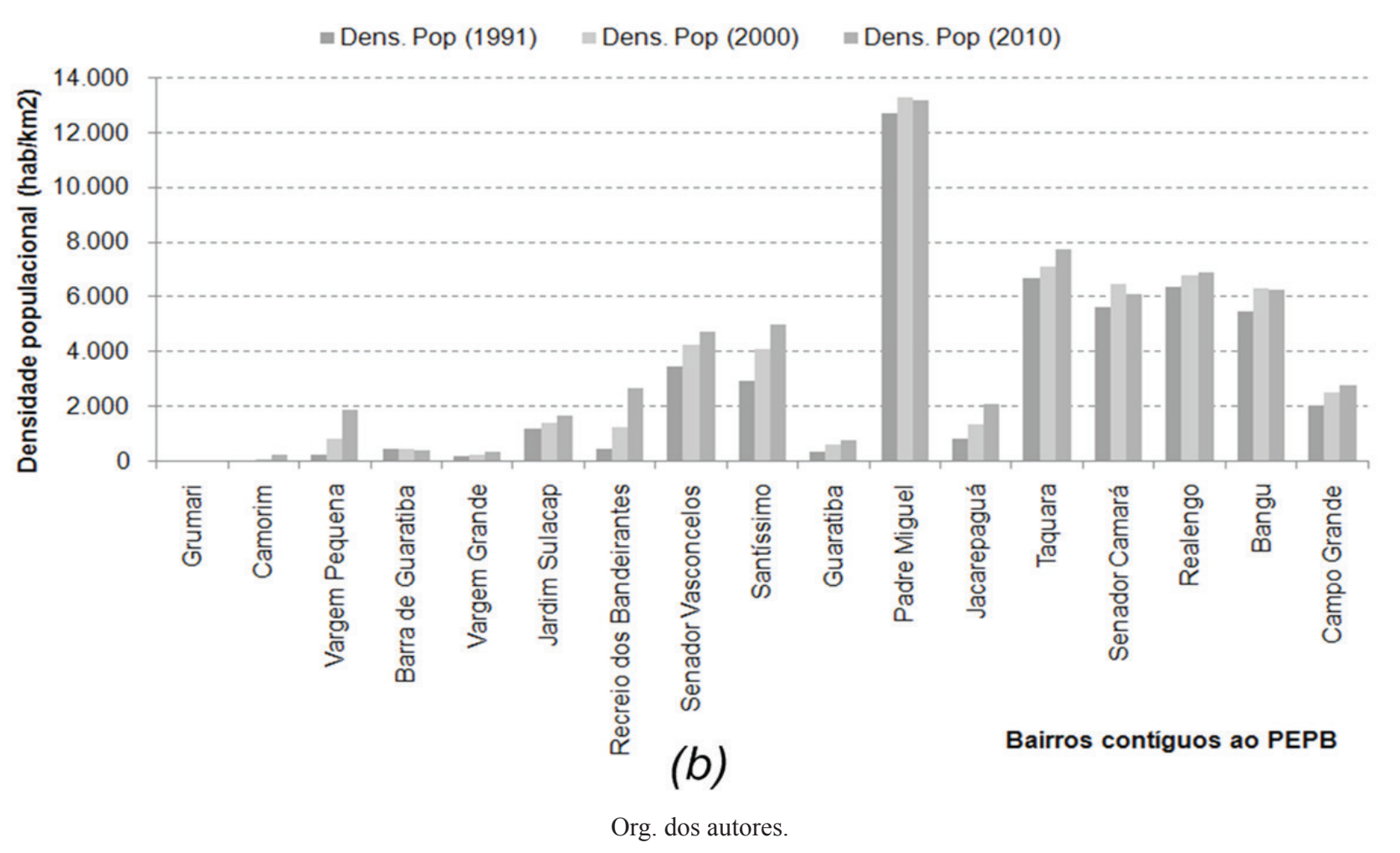

O trabalho de Costa (2002) estimou em 1997 cerca de 938 domicílios localizados no interior do PEPB, considerando como limite a cota 100 do Maciço da Pedra Branca e de seus contrafortes. A análise visual da imagem WorldView (2010/2011), e os dados do censo de 2010, permitiram estimar 1.181 domicílios no interior do PEPB (considerando todos os bairros limítrofes ao Parque), considerando apenas a cota 100 do Maciço da Pedra Branca, acordado com o INEA em 2011. Estes dados indicam que houve um aumento de domicílios dentro do PE da Pedra Branca de 20,6\% entre 1997 e 2011 (de 938 domicílios em 1997 - ver Costa (2002) - para 1.181 domicílios em 2011). Esse aumento de domicílios indica indiretamente um crescimento populacional no interior do Parque, o qual deve continuar em crescimento de acordo com o potencial para expansão que a região prevê para os próximos anos devido aos projetos: (a) BRT Transoeste no trecho entre Barra da Tijuca e Santa Cruz; (b) expansão da linha de metrô entre zona sul e zona oeste; (c) abertura do túnel da Grota Funda para o tráfego de veículos no sentido Recreio dos Bandeirantes-Guaratiba; (d) e duplicação de perimetrais.

Essa situação acompanhada do avanço da mancha urbana e aumento populacional sem con- siderar o conjunto de infraestrutura básica, tem exercido forte pressão sobre a cobertura florestal e a biodiversidade do PEPB (ver trabalhos de COSTA, 2002; OLIVEIRA, 2005; SATHLER, 2009; 2010), situação também observada em diversos trabalhos em áreas protegidas (ver PACHECO et al., 1992; NEWMARK et al., 1994; DEAN, 1995; BRANDON, 1998; FERREIRA, 1993; 2004, FERREIRA et al., 2004; RODRIGUES; BONONI, 2008; PORTER-BOLLAND et al., 2012).

\section{Questão fundiária no PEPB}

Foram aplicados no total $316(\mathrm{n}=316)$ questionários, que representa $29 \%$ em relação ao total estimado de moradias situadas no PEPB, distribuídos em dez (10) bairros, de acordo com a abordagem adotada no trabalho. A Tabela 1 mostra a estimativa de domicílios por bairros e respectivas amostragens para o levantamento fundiário. 
Tabela 1. Número de entrevistados por bairro e total no entorno do PE da Pedra Branca.

\begin{tabular}{|c|c|c|c|}
\hline Bairros & $\begin{array}{c}\text { Estimativa de domicílios/moradias } \\
\text { (Imagens WorldView e Censo } \\
\mathbf{2 0 1 0}\end{array}$ & $\begin{array}{c}\text { Tamanho } \\
\text { amostra (por } \\
\text { bairros) }\end{array}$ & $\begin{array}{c}\text { Percentual - \% (ta- } \\
\text { manho da amostra } \\
\text { por bairros) }\end{array}$ \\
\hline Vargem Pequena & 6 & 5 & 83,3 \\
\hline Camorim & 12 & 9 & 75,0 \\
\hline Barra de Guaratiba & 60 & 29 & 48,3 \\
\hline Vargem Grande & 120 & 38 & 31,7 \\
\hline Campo Grande & 339 & 103 & 30,4 \\
\hline Jacarepaguá & 341 & 98 & 28,7 \\
\hline Recreio dos Bandeirantes & 18 & 4 & 22,2 \\
\hline Realengo & 112 & 21 & 18,8 \\
\hline Guaratiba & 49 & 6 & 12,2 \\
\hline Jardim Sulacap & 26 & 3 & 11,5 \\
\hline Total & $1.083^{*}$ & 316 & 29,2 \\
\hline
\end{tabular}

* Total estimado sem considerar os bairros onde não foram realizadas as entrevistas: Bangu, Senador Camará, Padre Miguel, Santíssimo, Senador Vasconcelos, Grumari e Taquara Org. dos autores.

A partir desse levantamento/entrevistas, foram organizados três tópicos de análise sobre a propriedade ou imóvel: (i) a forma de aquisição do imóvel, (ii) o tipo de documentação; (iii) o tempo de ocupação. (i) O levantamento sobre a forma de aquisição do imóvel mostrou que a Herança e Compra e Venda foram as formas de aquisição mais frequentes, representando $36,1 \%(n=114)$ e $35,1 \%(n=111)$, respectivamente, do total de entrevistados sobre o modo de aquisição do imóvel. O restante dos entrevistados respondeu que obtiveram o imóvel por Posse (8,9\%), ou por Outra forma de aquisição $(17,7 \%)$, ou não responderam (SR - sem resposta) $-2,2 \%$. De fato, Outras formas de aquisição do imóvel ainda possui uma proporção significativa $(17,7 \%, \mathrm{n}=56)$, corroborando com os resultados de Costa (2002), que observou que muitos moradores no interior do PEPB não possui qualquer tipo de documentação que comprove a forma de aquisição das mesmas, sobretudo na vertente leste do Parque (quase em sua totalidade). Vargem Pequena e Vargem Grande (situados na vertente leste) são os bairros com maior proporção de entrevistados que disseram que adquiriram o imóvel por Outra maneira, com respectivamente $60 \%$ e $39,5 \%$. A Figura 3 mostra a distribuição dos 10 bairros analisados segundo a origem e aquisição do imóvel. 
Figura 3. Bairros analisados segundo a aquisição do imóvel $\left(\mathrm{n}_{\text {total }}=316\right) . *(\mathrm{SR} / \mathrm{NR}=$ Sem Resposta/Não Respondeu).

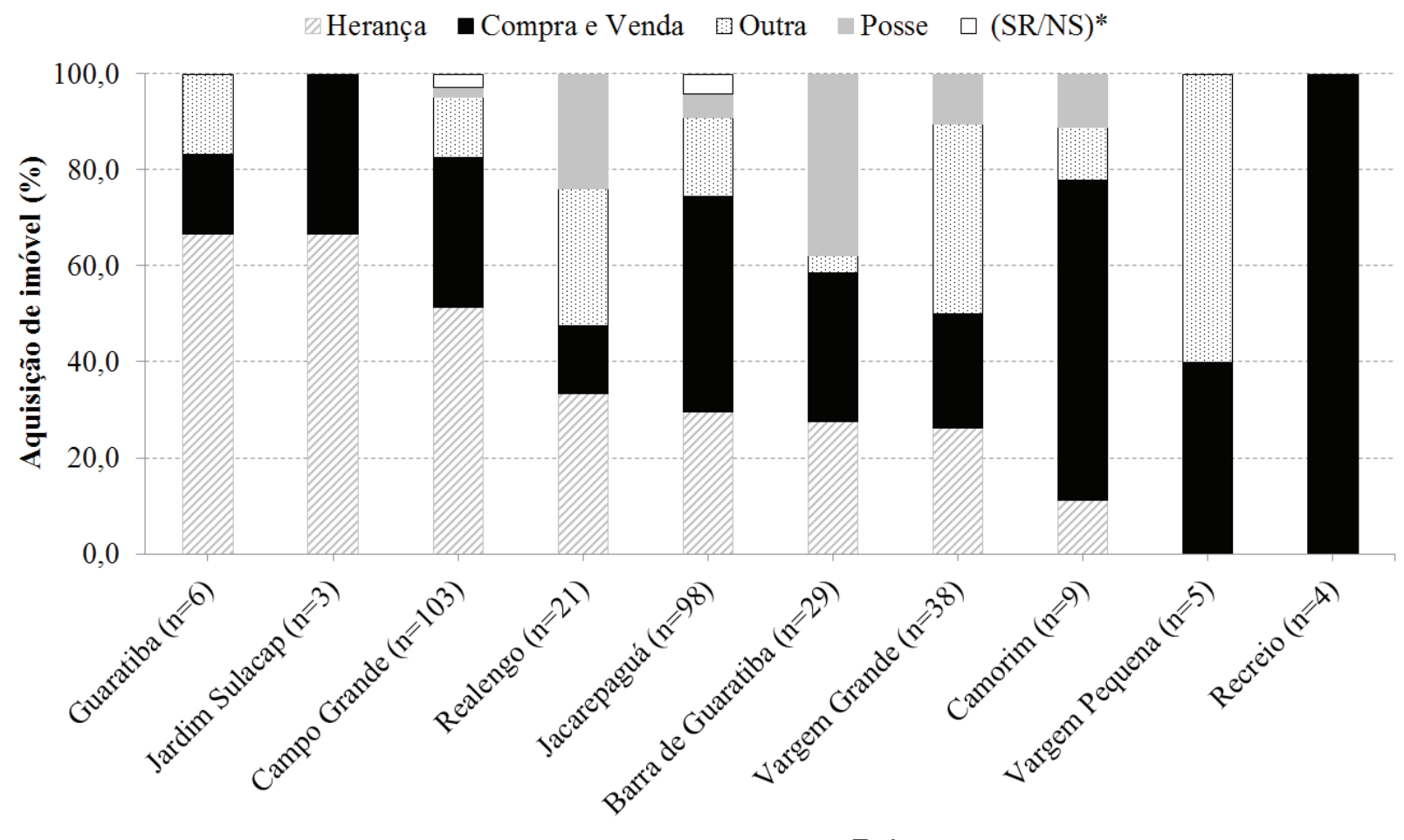

Bairros

Org. dos autores.

Em relação ao tipo de aquisição por Heran$c ̧ a$, as respostas mais frequentes estão situadas nos bairros de Guaratiba, Jardim Sulacap, Campo Grande e Realengo, com pelo menos $1 / 3$ dos entrevistados terem dito que o imóvel foi adquirido por Herança. Em termos relativos, deve-se destacar que os bairros da vertente oeste (Campo Grande e Realengo) são aqueles com um maior "peso" nessas respostas, uma vez que são bairros mais amostrados.

Os bairros do Recreio, Camorim e Jacarepaguá são aqueles com maior percentual de pessoas entrevistadas que disseram que o imóvel foi obtido por Compra e Venda, com pelo menos $45 \%$ dos entrevistados. A Posse representa 37,9\% somente no bairro da Barra de Guaratiba (vertente sul). De fato, Barra de Guaratiba (e Guaratiba como um todo) tem o predomínio de posseiros na região (SIQUEIRA, 2004; MOTA, 2009; ITPA, s.d.), além de ter sido observado esse predomínio na maior parte do levantamento de campo. De acordo com Siqueira (2004), em 1750, Don Fradique de Quevedo Rondon doou partes de suas terras de Guaratiba para a Matriz de São Salvador do Mundo de Guaratiba (denominada Fábrica da Matriz de Guaratiba). A Fábrica da Matriz de Guaratiba arrendava glebas da terra já ocupadas a seus posseiros, mas como estes vinham cumprindo as cláusulas de doação, não concordavam com um levantamento topográfico da região com receio de que as terras fossem vendidas. De acordo com Siqueira (2004), com o passar do tempo, alguns deixavam transparecer que as terras pertencentes à Fábrica da Matriz de Guaratiba tinham sido vendidas para a Companhia Carioca de Terrenos e Construções, onde coube a mesma a dar a escritura de quitação a 63 posseiros e respeitar suas propriedades, mesmo que fossem de seus sucessores. Entretanto, o processo de expedição das escrituras em favor dos posseiros ainda não foi realizado (SIQUEIRA, 2004). Além disso, no início do século 19, foi o momento em que os posseiros começaram a aparecer na história fundiária de Guaratiba como protagonistas envolvidos em ações de manutenção de posse; de medição e demarcação de terras; de pedidos de terras 
devolutas localizadas nas terras que teve origem da sesmaria de Manoel Veloso Espinha (MOTA, 2009).

(ii) No levantamento sobre o tipo de documentação do imóvel, 45,6\% ( $\mathrm{n}=144)$ disseram que não possuem nenhum tipo de documentação que seja Escritura, Matricula/Registro ou Declaração, Contrato ou Recibo (para mais detalhes sobre os documentos oficiais que configuram a base legal da administração e da organização fundiária brasileira ver Mota (2009)). Desse percentual, pelo menos 3 bairros têm mais do que a metade dos entrevistados que responderam que Não Possui nenhuma documentação: Jacarepaguá
(66,3\%), Camorim (55,6\%) e Realengo (52,4\%). Essa situação chama a atenção nos bairros de Jacarepaguá e Realengo, bairros relativamente mais amostrados.

Em relação aos que declaram algum tipo de documentação, o maior percentual é a documentação do tipo Declaração - 13\%, seguido de Escritura - 11\%, Procuração - 8,5\% e Registro (RGI) - 4,1\%, mostrando que a situação da falta de documentação/registro de propriedade analisada no período de 1997-2002 por Costa (2002) ainda permanece na região do PEPB (ver Figura 4).

Figura 4. Bairros analisados segundo o tipo de documentação do imóvel $\left(\mathrm{n}_{\text {total }}=316\right)$.

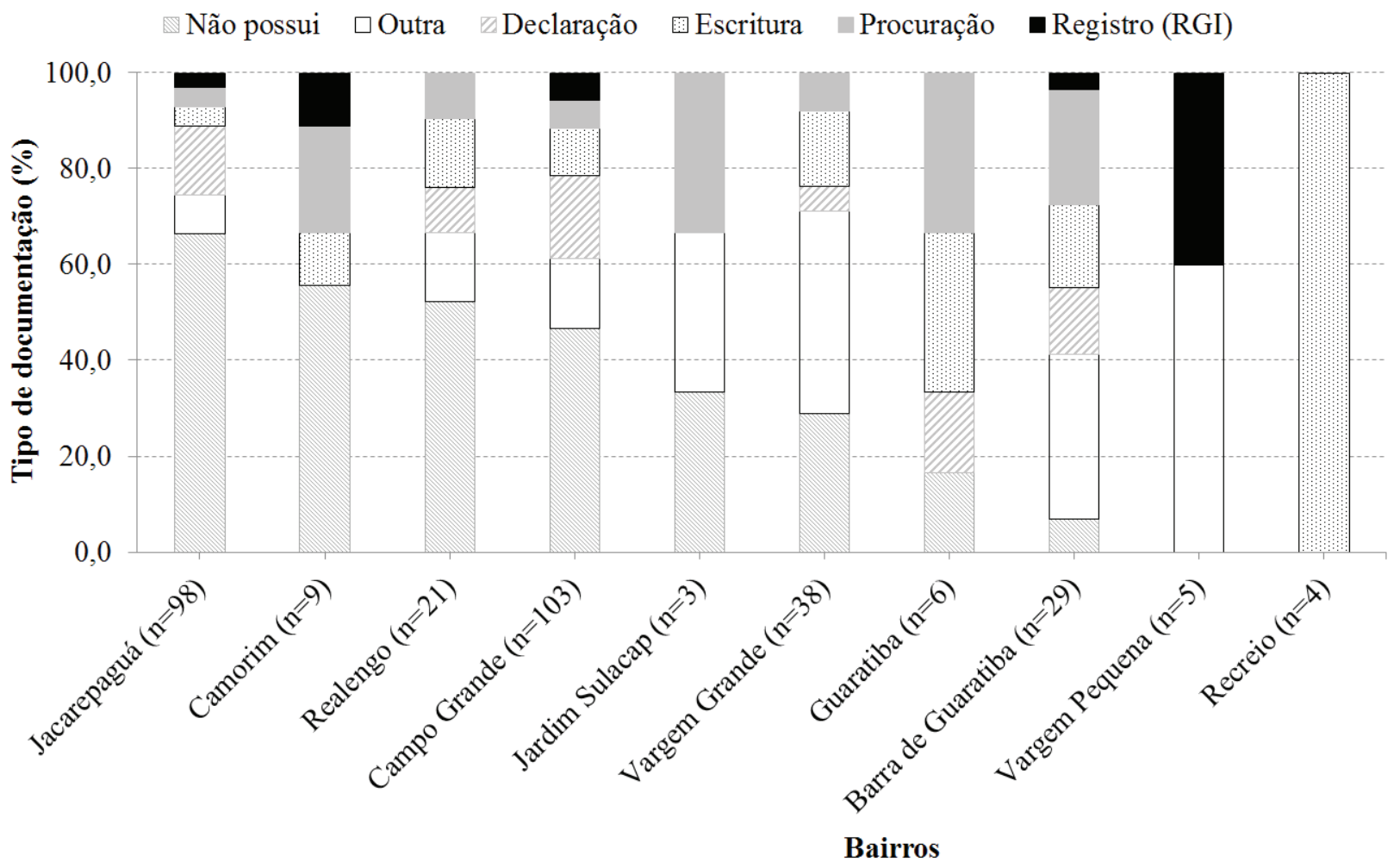

Org. dos autores.

No levantamento de campo, constatou-se serem escrituras de Compra e Venda, em sua maioria vendidas pelo Banco de Crédito Móvel. De acordo com Costa (2002), o Banco de Crédito Móvel hipotecou parte das terras dos beneditinos em meados do século 19, que foram passadas por herança pela filha D. Vitória (terras de Gonçalo Corrêa de Sá). O Banco de Crédito Móvel, por sua vez, vendeu parte das terras a diversos pequenos proprietários, dentre eles, em
Vargem Grande e Vargem Pequena. Apesar do baixo percentual do levantamento de tipo de documentação, observa-se que a Escritura Pública e o Registro de Matrícula têm maiores proporções (pelo menos 1/3) nas entrevistas dos bairros de Guaratiba, Recreio e Vargem Pequena (Figura 5).

(iii) Em relação ao tempo de ocupação na propriedade, com base nas respostas obtidas, foi feito um agrupamento das entrevistas que apresentaram res- 
postas com: (a) tempo de ocupação há mais de 37 anos, ou seja, antes da criação do PEPB (1974) e (b) tempo de ocupação igual ou menor do que 37 anos, após a criação do PEPB. Embora exista certa subjetividade nas respostas sobre o tempo de ocupação no imóvel, fragilidade já constatada no levantamento feito por ITPA(s.d), no qual os moradores mostraram-se pouco confortáveis com os questionamentos do levantamento fundiário e muitos recusaram-se a responder, ou claramente omitiam informações, essa categorização permite verificar aqueles (proprietários/posseiros) que residiam antes (há mais de 37 anos) e depois (menos do que 37 anos) da criação do PEPB (criado em 1974). Assim, verificou-se que $61,7 \%$ do total de entrevistados responderam que moram a menos do que 37 anos ( $n=195)$, enquanto $31,3 \%$ disseram morar há mais de 37 anos $(n=99)$. Pelo menos $1 / 3$ dos entrevistados (relativo ao total amostrado em cada bairro) responderam que residem a mais de 37 anos na mesma moradia/residência, referentes aos bairros de Barra de Guaratiba (51,7\%), Guaratiba (50\%) - vertente sul, Campo Grande (45,6\%) - vertente oeste e Vargem Grande (31,6\%) - vertente leste (ver Figura 5).

Figura 5. Bairros analisados segundo o tempo de ocupação do imóvel $\left(\mathrm{n}_{\text {total }}=316\right)$ * $(\mathrm{SR}=\mathrm{Sem}$ Resposta $)$

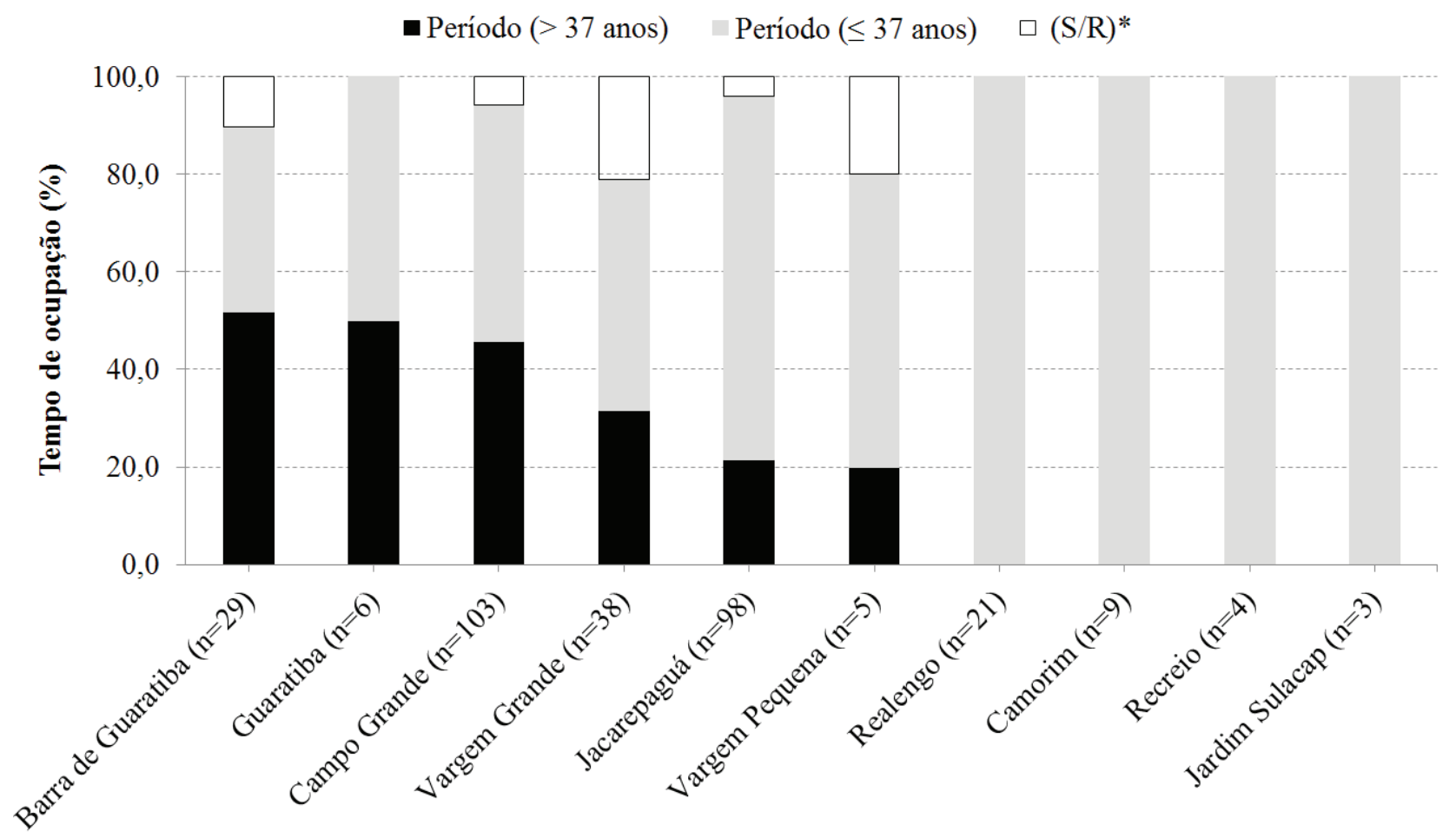

Bairros

Org. dos autores.

Com base nesse levantamento fundiário e em trabalhos de Costa (2002) e Sathler (2010), foram apontadas pelos menos seis zonas $(Z)$ que traduzem algumas tipologias de ocupação no interior ou limite do PEPB. A Figura 6 e as Tabela 2 (zonas com ocupações predominantemente urbanas ou mistas) e Tabela 3 (zonas com ocupações predominantemente rurais ou atividades de subsistência), analisados em conjunto, mostram uma heterogeneidade de ocupações no interior do PEPB. Ainda assim é possível indicar alguns padrões, pois observou-se que aqueles que moram há mais de 37 anos (ocupações mais antigas) no interior do PEPB encontram-se nas vertentes leste e oeste, onde predominam ocupações com características rurais, enquanto na vertente norte predominam ocupações com características urbanas, tanto de baixa quanto de média e alta renda. 
Figura 6. Distribuição de bairros contíguos ao PEPB segundo a proporção de respostas dos entrevistados sobre o tempo de ocupação

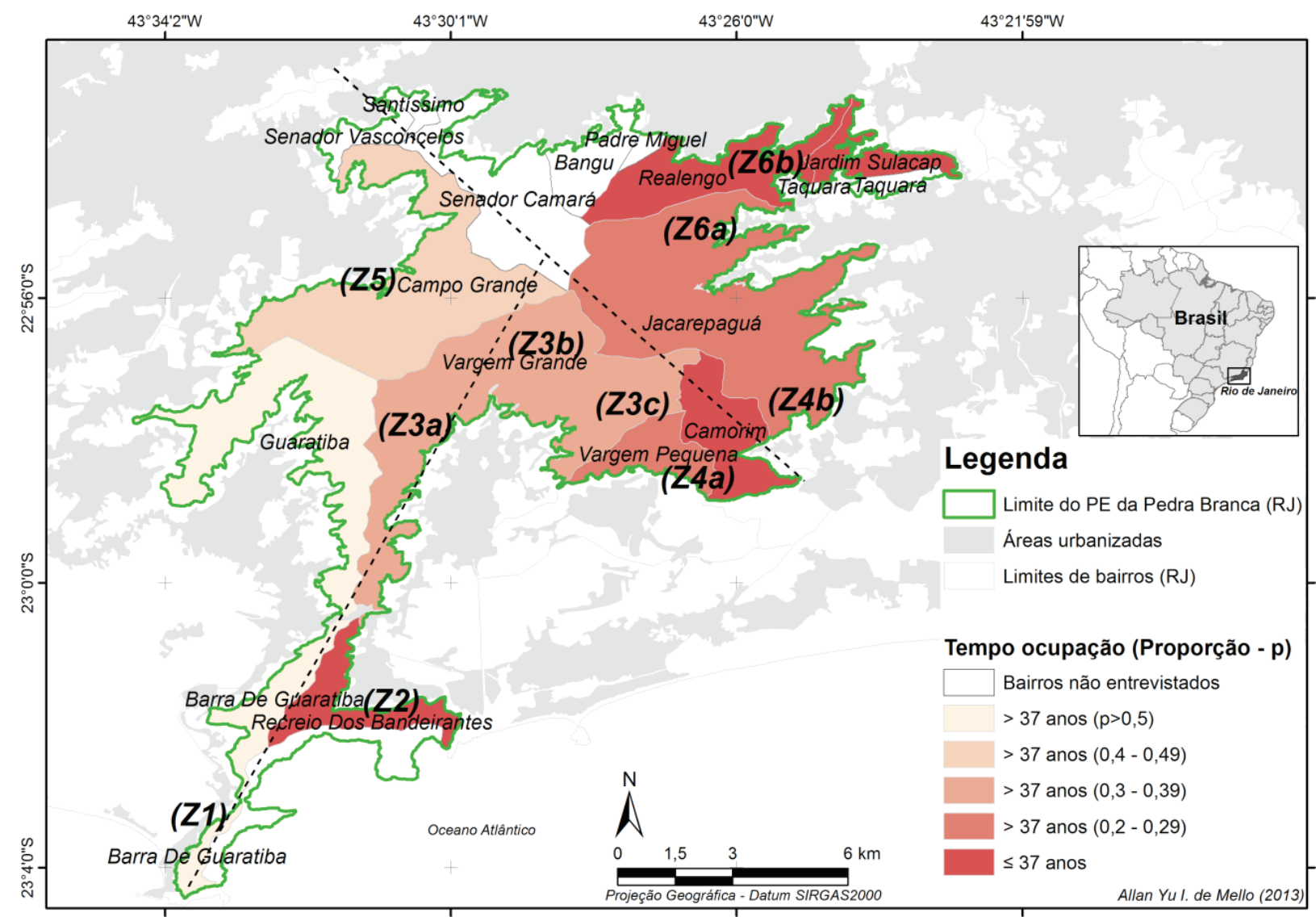

( $\mathrm{p}$ = proporção de pessoas que moram há mais de 37 anos dividido pelo total de pessoas entrevistadas no bairro) e indicação de zonas (Z) de diferentes tipologias.Exemplo: $\mathrm{p}>05$ corresponde a mais de $50 \%$ das pessoas entrevistadas no bairro responderam que moram há mais de 37 anos na residência). Org. dos autores. 
Questão fundiária em áreas protegidas: Uma experiência no Parque Estadual da Pedra Branca (PEPB), Rio de Janeiro, Brasil Allan Yu Iwama, Fábio Bueno de Lima, Angela Pellin

Tabela 2. Identificação de zonas de ocupações com predomínio de ocupações urbanas ou mistas (rural e/ou urbana) na área de interesse do estudo.

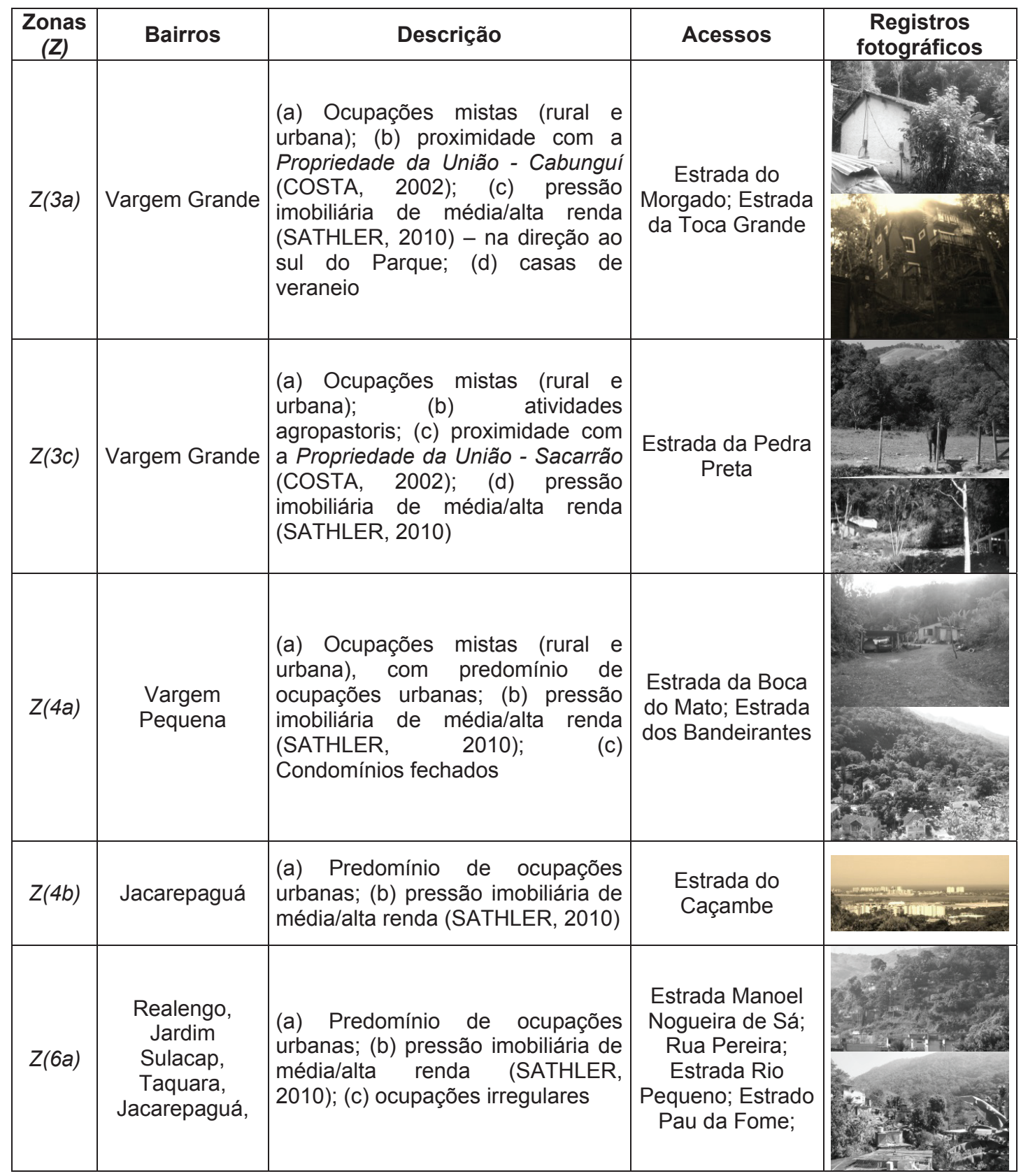

Org. dos autores. 
Tabela 3. Identificação de zonas de ocupações com predomínio de ocupações rurais ou atividades de subsistências na área de interesse do estudo.

\begin{tabular}{|c|c|c|c|c|}
\hline $\begin{array}{l}\text { Zonas } \\
\text { (Z) }\end{array}$ & Bairros & Descrição & Acessos & $\begin{array}{c}\text { Registros } \\
\text { fotográficos }\end{array}$ \\
\hline$Z(1)$ & $\begin{array}{l}\text { Barra de } \\
\text { Guaratiba, } \\
\text { Guaratiba }\end{array}$ & $\begin{array}{l}\text { (a) Ocupações mistas (rural e } \\
\text { urbana); (b) predomínio de } \\
\text { posseiros (SIQUEIRA, 2004); (c) } \\
\text { áreas de cultivo de bananas } \\
\text { (SATHLER, 2010); (d) condomínios } \\
\text { fechados }\end{array}$ & $\begin{array}{l}\text { Estrada da } \\
\text { Vendinha; Rua } \\
\text { Samaúma }\end{array}$ & \\
\hline$Z(2)$ & $\begin{array}{c}\text { Recreio dos } \\
\text { Bandeirantes, } \\
\text { Grumari }\end{array}$ & $\begin{array}{l}\text { (a) Predomínio de ocupações rurais } \\
\text { e (b) agricultura de subsistência; (c) } \\
\text { área nas proximidades de } \\
\text { plantações de banana (SATHLER, } \\
2010) ; \quad \text { (d) presença de } \\
\text { condomínios fechados }\end{array}$ & $\begin{array}{c}\text { Estrada de } \\
\text { Grumari; Estrada } \\
\text { dos Bandeirantes }\end{array}$ & \\
\hline$Z(3 b)$ & Vargem Grande & $\begin{array}{l}\text { (a) Predomínio de ocupações rurais } \\
\text { e (b) agricultura de subsistência }\end{array}$ & $\begin{array}{l}\text { Estrada Mato Alto } \\
\text { do Pacuí }\end{array}$ & \\
\hline$Z(5)$ & Campo Grande & $\begin{array}{l}\text { (a) Predomínio de ocupações rurais } \\
\text { e mistas; (b) agricultura de } \\
\text { subsistência; (c) influência da rede } \\
\text { elétrica }\end{array}$ & $\begin{array}{c}\text { Estrada do } \\
\text { Viegas; Estrada } \\
\text { das Tachas }\end{array}$ & \\
\hline$Z(6 b)$ & Realengo & (a) Predomínio de ocupações rurais & $\begin{array}{l}\text { Estrada dos } \\
\text { Teixeiras }\end{array}$ & \\
\hline
\end{tabular}

Org. dos autores.

Cabe destacar que, em Vargem Grande (zonas $Z(3 a, c))$, Vargem Pequena e Camorim (zona $Z(4 a))$, e Jacarepaguá (zona Z(4b)), há o predomínio de ocupações urbanas de médio ou alto padrão (COSTA, 2002; SATHLER, 2010) que se deram há menos de 37 anos, configurando zonas de ocupação mais recentes, enquanto na zona $Z(3 b)$ há o predomínio de ocupações rurais que já se encontravam na região antes da criação do PEPB. No entanto, não é possível fazer uma generalização. Vargem
Grande, por exemplo, na estrada do Mato Alto do Pacuí $-Z(3 c)$ foram entrevistadas pessoas que moram há mais de 37 anos no interior do PEPB e que, em sua maioria, utilizam-se de agricultura para subsistência. Há também aqueles que saem para trabalhar "fora" para conseguir seu próprio sustento. No Recreio dos Bandeirantes Z(2), assim como em outros bairros da vertente leste e oeste, há uma heterogeneidade de situações, pois apesar de existir o predomínio de pequenos agricultores e ocupações com 
características rurais no interior do Parque, há também ocupações em seu entorno imediato de condomínios particulares. No Recreio, em particular, ainda que os entrevistados tenham respondido que moram há menos de 37 anos, foi observado durante as entrevistas que as propriedades foram compradas do Banco de Crédito Móvel, indicando estas famílias herdaram a propriedade de outras gerações, que já se encontravam nesta região.

Alguns locais dos bairros de Realengo, Jardim Sulacap, Taquara e Jacarepaguá, representados pelas zonas $Z(6 a, b)$ também ilustram a diversidade de situações encontradas no interior ou proximidades do Parque, com um predomínio de áreas urbanas na zona $Z(6 a)$ e de áreas rurais na zona $Z(6 b)$. A Lei no 2.393/1995 (RIO DE JANEIRO, 1995), assegurando que às populações residentes há mais de 50 anos em Unidades de Conservação, o direito real de uso das áreas ocupadas ficando, como contrapartida, obrigadas a participar de sua preservação, recuperação, defesa e manutenção. Entretanto, ainda é visto residentes que ocupam o interior do PEPB, mais recentemente, agravando o conflito de terras no PEPB.

De acordo com o NUREF (o núcleo responsável pelas ações de regularização fundiária nesta UC), a regularização fundiária de uma UC se constitui em desapropriação e na consolidação documental e jurídica da transferência desses imóveis para o Estado. Entretanto, considerando o alto grau de complexidade da situação fundiária atual do PEPB e o grande número de moradores desta UC torna-se imprescindível que o planejamento de sua regularização fundiária seja realizado com base na definição de áreas prioritárias. A situação fundiária em áreas protegidas é bastante complexa e, portanto, é necessária a implementação de uma série de estratégias de longo prazo, buscando o menor conflito social possível. Deve-se considerar também que a regularização fundiária deva ser feita com um plano acompanhado de prazo no momento da criação de uma unidade de conservação ou o mais breve possível (ver OLIVEIRA, 2010). No âmbito desse trabalho podem ser feitos os seguintes apontamentos ou gargalos a serem implementados: (i) levantamento sistemático de informações em cartórios, para que seja criado um cadastro dos proprietários, das famílias e dos imóveis do PEPB; (ii) criação de grupos de trabalho para a minimização de conflitos fundiários, considerando que a multi e interdisciplinaridade são fundamentais para o sucesso de ações dessa natureza; (iii) implementação de programas de educomunicação ambiental, visando esclarecimentos sobre a preservação do PEPB, como um fator de melhoria da qualidade de vida da população local; (iv) formalização de acordos entre os moradores do Parque e entorno visando minimizar os atuais conflitos ocasionado pela demora em se resolver a questão fundiária do PEPB.

\section{CONCLUSÕES}

Nas últimas três décadas houve um aumento populacional em bairros contíguos ao PEPB. Esse aumento, associado com a urbanização do entorno do PEPB indica situações de pressão para a conservação dessa UC e com fortes implicações para a situação fundiária. Este trabalho indicou um aumento de moradias e pessoas no interior do $\mathrm{PEPB}$ e, os resultados do levantamento fundiário revelaram uma ocupação antrópica bastante diversificada, com moradores de classe alta, média e baixa, incluindo áreas de favelas; agricultores que moram e sobrevivem das atividades econômicas desenvolvidas no interior dessa UC; e até mesmo residentes temporários que utilizam o local para "veraneio". Essa diversidade de ocupações tem forte implicação sobre a questão fundiária, levando a uma fragmentação de situações - seja pelo tipo de aquisição ou documento do imóvel ou pelo tempo de residência.

Nesse sentido, esse estudo ressalta que a questão fundiária não deve ser sintetizada apenas em resoluções como a desapropriação, com a retirada da população residente de seu interior, acompanhada de indenização. Como a estrutura fundiária é muito complexa, pois envolve ocupações contínuas e crescentes da terra por posseiros e proprietários urbano-rurais, é fundamental observar as dinâmicas sociais sobre questão da terra, bem como outros direitos de propriedade que se gestaram durante a colonização, pois as circunstâncias e o contexto social em que são criadas as áreas protegidas influenciam toda a gestão de sua área de abrangência (ver trabalhos de BRANDON, 1998; COSTA, 2002; RYLANDS; BRANDON, 2005; MOTA, 2009). Em situações críticas, onde a quantidade e o tempo de ocupação dos residentes inviabiliza qualquer ação de reassentamento, seria razoável considerar o redimensionamento, recategorização e consolidação dessas áreas protegidas, que seja compatível com o desenvolvimento dos residentes (CMA/ 
CNRBMA, 1996; BARBORAK, 1997; COSTA, 2002; SATHLER, 2009; PORTER-BOLLAND et al., 2012). Essa ação deve ser observada em diversas Unidades de Conservação do Brasil, uma vez que os problemas são semelhantes, todavia há peculiaridades em cada unidade ou área protegida que exige tratamentos diferenciados para modificação do perímetro da área original. É fundamental que estudos mais detalhados sejam conduzidos no âmbito da implementação do Programa de Regularização Fundiária desse plano de manejo, com ênfase para a realização de um censo de todas as propriedades localizadas no interior do PEPB, uma vez que os resultados desse trabalho não esgotaram o assunto. Finalmente, a utilização de dados de imagens de satélite, do Censo Demográfico e levantamento em campo possibilitaram uma estimativa da população localizada no interior do PEPB, indicando que o uso de geotecnologias pode ser uma importante ferramenta para a gestão de áreas protegidas.

\section{AGRADECIMENTOS}

Ao PPNMA-RJ pelo suporte financeiro. À equipe de trabalho do IPÊ, responsável pela elaboração do Plano de Manejo do PEPB. Ao INEA, conselheiros, gestores e moradores do PEPB que contribuíram com este trabalho.

\section{REFERÊNCIAS}

AZEVEDO, P.U.E. Implementando as unidades de conservação: particularidades da regularização fundiária. In: MILANO, M. S. (Org.). Unidades de conservação: atualidades e tendências. Curitiba: Fundação O Boticário, 2002. p. 17-30.

BARBORAK, J. Mitos e Realidade da Concepção Atual de Áreas Protegidas na América Latina. In: I CONGRESSO BRASILEIRO DE UNIDADES DE CONSERVAÇÃO, Curitiba. Anais... v. 1, p.39-47, 1997.

BRANDON, K. Perils to park: the social context of threats. In: BRANDON, K.; REDFORD, K.H.; SANDERSON, S. (Eds.). Parks in peril: people, politics, and protected areas. Island Press: Washington, D.C. p. 415-439, 1998.
BRASIL - Constituição 1824, de 25 de março de 1824. Constituição Política do Império do Brasil, 1824.

BRASIL - Lei $n^{\circ}$. 601, de 18 de setembro de1850. Dispõe sobre as terras devolutas do Império, 1850.

BRASIL-Lei $n^{\circ}$. 9.985, de 18 de julho de 2000. Institui o Sistema Nacional de Unidades de Conservação da Natureza e dá outras providências, 2000.

CMA/CNRBMA-Consórcio Mata Atlântica e Conselho Nacional da Reserva da Biosfera da Mata Atlântica. In: GUATURA, I.S.; et al. (Orgs.). Questão Fundiária: Roteiro para Solução dos Problemas fundiários nas Áreas Protegidas. 2a ed. São Paulo: IF-SP, 1996.

COSTA, N.M.C. Análise do Parque Estadual da Pedra Branca (RJ) por Geoprocessamento: uma contribuição ao seu Plano de Manejo. Tese (Doutorado). Rio de Janeiro: UFRJ, 2002.

COSTA, N.M.C.; COSTA, V.C.; CONCEIÇÃO, R.S.; RIBEIRO, J.V.M. Fragilidade ecoturística em áreas de atrativos no Parque Estadual da Pedra Branca (RJ). GeoUERJ, v.2, n.19, p.138-160, 2009.

DEAN, W. With broadax and firebrand: the destruction of the Brazilian Atlantic Forest. Berkeley: University of California Press, 1995.

FERREIRA, L. C. Os fantasmas do vale. Campinas: Editora da Unicamp, 1993.

FERREIRA, L. C. et al. Conflitos sociais em áreas protegidas no Brasil: moradores, instituições e ONGs no Vale do Ribeira e Litoral Sul, SP. Ideias, v.8, n.2, p.115-150, 2002.

FERREIRA, L. C. Dimensões humanas da biodiversidade. Ambiente \& Sociedade, v.7, n.1,p.5-29, 2004.

FRIDMAN, F. Donos do Rio em Nome do Rei: uma história fundiária da cidade do Rio de Janeiro. $2^{\mathrm{a}}$. ed. Rio de Janeiro: Jorge Zahar Editor e Editora Garamond, 1999. $304 \mathrm{p}$. 
FRIDMAN, F. Freguesias do Rio de Janeiro ao final do século XVIII. In: PONTUAL, V.; LORETTO, R.P. (Orgs.). Cidade, território e urbanismo. $1^{\mathrm{a}}$. ed. Olinda: Centro de Estudos Avançados da Conservação Integrada, v. 1, p. 205-219, 2009.

IBGE - Instituto Brasileiro de Geografia e Estatística. Arquivos de Microdados e Censo Demográfico 1991, 2000 e 2010. Rio de Janeiro: IBGE, 2011.

IEF - Instituto Estadual de Florestas. Projeto Floresta da Pedra Branca. Rio de Janeiro, 1992. 55 p.

INEA - Instituto Estadual do Ambiente do Rio de Janeiro. Ciência para Gestão ou Gestão para a Ciência?. In: MENDES, C.P.A.; BANDEIRA, F.C.S. (Coords.). Rio de Janeiro: INEA, 2009. 119 p.

INEA - Instituto Estadual do Ambiente do Rio de Janeiro. In: MAGNANINI, A. et al. (Orgs.). Roteiro Metodológico para Elaboração de Planos de Manejo: Parques Estaduais, Reservas Biológicas, Estações Ecológicas. Rio de Janeiro: INEA, 2010. 115 p.

IPP - Instituto Municipal de Urbanismo Pereira Passos. Secretaria Municipal de Urbanismo (SMU). Anuário Estatístico da Cidade do Rio de Janeiro. Rio de Janeiro: PMRJ, 2000. 864 p.

ITPA - Instituto Terra de Preservação Ambiental. Plano de Estruturação do Parque Estadual da Pedra Branca. In: Costa, N.M.C. et al. (Coord.). Rio de Janeiro: sem ano de publicação (s/ano).

FERNANDEZ, A.C.F. A construção social do Parque Estadual da Pedra Branca: do castelo das águas ao parque de carbono. In: MENDES, C.P.A.; BANDEIRA, F.C.S. (Coords.). Ciência para Gestão ou Gestão para a Ciência?. Rio de Janeiro: INEA, 2009, p-17-21.

MARTINE, G. População, Meio Ambiente e Desenvolvimento: O Cenário Global e Nacional. In: População, Meio Ambiente e Desenvolvimento - Verdades e Contradições. São Paulo, UNICAMP, p.21-42, 1996.
MOTA, M.S.C. Nas terras de Guaratiba - uma aproximação histórico-jurídica às definições de posse e propriedade da terra no Brasil entre os séculos XVI$X I X$. Tese (Doutorado). Rio de Janeiro: UFRRJ, 2009.

NEWMARK, W.D.; MANYANZA, D.N.; GAMASSA, D.M.; SARIKO, H.I. The conflict between wildlife and local people living adjacent to protected areas in Tanzania: Human density as a predictor. Conservation Biology, v.8, p.249-255, 1994.

OLIVEIRA, L.J.D. Regularização fundiária de unidades de conservação. Boletim Científico. Brasília: ESMPU, n. 32/33, p. 143-176, 2010.

PACHECO, R.; LOUREIRO, M. R.; FINGERMANN, H.; AMARAL, H.K.; MACDOWELL, S. Atores e conflitos em questões ambientais urbanas. Espaço e Debates, n.35, p. 4-20. 1992.

PORTER-BOLLAND et al. Community managed forests and forest protected areas: An assessment of their conservation effectiveness across the tropics. Forest Ecology and Management, v.268, p.6-17, 2012.

RIO DE JANEIRO - Lei Estadual no. 2.377, de 28 de junho de1974. Cria o Parque Estadual da Pedra Branca e dá outras providências, 1974.

RIO DE JANEIRO - Lei Estadual $n^{\circ}$. 2.393, de 20 de abril de1995. Dispõe sobre a permanência de populações nativas residentes em UC do estado do Rio de Janeiro, 1995.

ROCHA, L.M.G. Os parques nacionais do Brasil e a questão fundiária: o caso do Parque Nacional da Serra dos Órgãos. Dissertação (Mestrado). Niterói-RJ: UFF, 2002.

ROCHA, L.M.G.; DRUMMOND, J.A.; GANEM, R.S. Parques Nacionais Brasileiros: problemas fundiários e alternativas para a sua resolução. Rev. Sociol. Polit., Curitiba, v. 18, n. 36, p. 205-226, 2010. 
RODRIGUES, R.R.; BONONI, V.L.R. (Orgs). Diretrizes para conservação e restauração da biodiversidade no Estado de São Paulo. São Paulo: IB, 2008. 248p.

RYLANDS, A.B.; BRANDON, K. Brazilian Protected Areas. Conservation Biology, v.19, n.3, p.612-618, 2005.

SATHLER, E.B. Síntese fundiária do Parque Estadual da Pedra Branca-PEPB. In: MENDES, C.P.A.; BANDEIRA, F.C.S. (Coords.). Ciência para Gestão ou Gestão para a Ciência?. Rio de Janeiro: INEA, 2009, p-10-16.

SATHLER, E.B. Os "espaços de incerteza", a "desterritorialização subjetiva" e o "pacto da conservação": perspectivas de uma geografia socioambiental das áreas naturais protegidas. Tese (Doutorado). Rio de Janeiro: UFF, 2010.

SIQUEIRA, F.A. Barra de Guaratiba, Sua Vida, Seu Povo, Seu Passado. Rio de Janeiro: Edição Independente, 2004. $155 \mathrm{p}$.

SMA - Secretaria do Meio Ambiente de São Paulo (Estado). Regularização fundiária em Unidades de Conservação: as experiências dos Estados de São Paulo, Minas Gerais e Rio de Janeiro. In: Honora, A.C.C et al. (Orgs.). São Paulo: IMESP, 2009. $168 \mathrm{p}$.

SOARES, D.G. Parque Estadual da Pedra Branca e Comunidade Monte da Paz: tensões e conflitos para os moradores de uma área protegida. Dissertação de Mestrado. Rio de Janeiro: UERJ, 2004.

SOARES, D.G. Entre a paz e a corrente: um estudo sobre as contradições, as tensões e os conflitos de moradores no Parque Estadual da Pedra Branca. In: MENDES, C.P.A.; BANDEIRA, F.C.S. (Coords.). Ciência para Gestão ou Gestão para a Ciência?. Rio de Janeiro: INEA, 2009, p-110-115.

VALLEJO, L.R.; CAMPOS, R.M.; SANTOS JÚNIOR, W.M. Contribuição ao estudo dos conflitos territoriais no Parque Estadual da Pedra Branca. In: MENDES, C.P.A.; BANDEIRA, F.C.S. (Coords.). Ciência para Gestão ou Gestão para a Ciência?. Rio de Janeiro: INEA, 2009, p-6-9. 